\title{
Promoting SME Innovation in China ${ }^{*}$
}

\author{
DOUGLAS ZHIHUA ZENG ${ }^{* *}$
}

China is at the critical cross road of transforming its development model from a resource and low-tech based one towards a more knowledge and technology intensive one. Evidence shows that Chinese enterprises, especially SMEs, are facing serious constraints in terms of human resources, technology acquisition and absorption, and access to finance and various innovation services. How to overcome these constraints is the key focus of an effective innovation strategy. This paper is intended to examine these key constraints through a diagnostic analysis, and to provide relevant policy suggestions and good international or domestic examples in various areas.

Keywords: China, Innovation, Enterprise Innovation, SME, Technology Diffusion, Cluster, University-Industry Linkage

This paper was initially conducted for the World Bank EASFP's China Enterprise Innovation Study, and the author is very grateful to Chunlin Zhang for his insightful guidance and input.

- Douglas Zhihua Zeng, Economist, Investment Climate Capacity Enhancement Program, The World Bank, 1818 H st., NW, Washington DC 20433, U.S.A.; Tel: +1-202-473-6618;

E-mail: Zzeng@worldbank.org 


\section{INTRODUCTION}

W

ith adequate incentives, business climate and financing, the effectiveness and efficiency of enterprise-led innovation is largely a function of innovation capacity of enterprises themselves. Anecdotal evidence and various studies show that Chinese enterprises, especially SMEs operating in traditional sectors and less developed regions, are facing serious constraints in terms of human resources, technology acquisition and absorption, and access to finance and various innovation services. How to overcome these constraints and enhance the innovation capacity of Chinese enterprises, especially SMEs, is the key focus of an effective enterprise innovation strategy. This paper is intended to identify the key constraints of China's enterprise (especially SMEs) innovation capacity through a diagnostic analysis, including two most recent surveys, and to provide relevant policy suggestions and international or domestic examples in the areas of human resources, research-industry linkages, technology diffusion, cluster development and innovation services.

\section{STRENGTHENING HUMAN RESOURCES CAPACITY FOR INNOVATION}

Highly educated and skillful talents are the key for innovation. Although China is not short of labors, the skillful people are still relatively scarce, which makes it harder for SMEs to recruit and retain these talents. This situation is exacerbated by the poor human resources management by many SMEs. Through better deployment of their limited human resources, SMEs may substantially strengthen their innovation capacity. A World Bank SME innovation survey of 367 Chinese firms in Zhejiang and Chongqing, conducted by the research team in 2007 (thereafter referred to as the "World Bank 2007 survey"l) shows that the "lack of qualified talents" is the second highest constraints for innovation, following the "lack of capital" (Table 1). In Zhejiang, the talents shortage is actually ranked as the number one constraint.

Based on this and other surveys as well as our field studies, it seems that SMEs need to improve their abilities in the following three areas related to human resources management.

- Managing in-bouse RED talents. SMEs, especially private ones, face common challenges in managing well-educated and experienced managerial and technical staff. Due to low wages, kinship-based management style and corporate culture, most high-end talents are not willing to stay long in private SMEs. The general skills shortage in China makes the situation even worse SMEs. Based on a survey of 465 Chinese enterprises by the ILO, the Chinese Enterprise Confederation and the Center for Labor Market Studies at the 
Table 1. MAJOR BARRIERS FOR INNOVATION

\begin{tabular}{l|c|c|c}
\multicolumn{1}{c|}{ Barriers } & Chongqing & Zhejiang & Total \\
\hline Too high economic risk & 2.53 & 3.07 & 2.77 \\
\hline Too high cost & 2.69 & 3.09 & 2.87 \\
\hline Lack of capital & 3.43 & 3.22 & 3.34 \\
\hline Stagnant internal mechanism & 2.1 & 3.25 & 2.74 \\
\hline Lack of technical information & 2.47 & 3.31 & 2.89 \\
\hline Lack of market information & 2.6 & 3.33 & 2.97 \\
\hline Lack of qualified talents & 2.9 & 3.63 & 3.24 \\
\hline Lack of intellectual property protection & 2.81 & 3.3 & 3.05 \\
\hline Constraining regulations and standards & 2.65 & 3.04 & 2.84 \\
\hline Lack of venture capital & 2.99 & 3.08 & 3.03 \\
\hline Insufficient feedbacks of customers to new products & 2.59 & 3.23 & 2.91 \\
\hline Lack of technical promotion services & 2.48 & 3.47 & 2.94 \\
\hline
\end{tabular}

NOTE: 1. unimportant; 2. somewhat important; 3. important; 4. very important; 5 . extremely important. SOURCE: World Bank SME innovation survey, 2007.

University of Leicester in the UK in 2000 , almost half (46.4\%) were experiencing difficulties in recruiting managers while almost one third (29.9\%) were having difficulty in recruiting technical staff. ${ }^{2}$ A survey by the China National Statistics Bureau in 2006 of 40 cities in China (thereafter will be referred as "CNSB Survey") shows that the R\&D personnel in private enterprises accounts for $5.0 \%$ of the total employees, lower than SOEs $(6.2 \%)$ and foreign enterprises (5.5\%). For all enterprises, "shortage of technological personnel" is the second highest obstacle for innovation, just next to "shortage of funding." 3 A field visit to Wenzhou in 2006 revealed that senior management and technical personnel such as chief operation officers, chief engineers and middle level managers tend to be paid below the market competitive rates. The World Bank 2007 survey shows that SMEs have great difficulties in many fronts of human capital, especially managing and retaining R\&D talents reflected on the high scores on items $d$, e, and $f$ (Table 2). This situation determines that the turnover of management and technical staff is quite high in SMEs, especially private ones. Most skilled people are not willing to sign labor contract, or just sign a one or two-year contract. High turnover adds to the problem of technology and trade secrets loss. Therefore, a better human resources management is definitely needed to help retain talents and motivate them to innovate.

- Building innovation management capacity. Interviews with government officials and entrepreneurs in Wenzhou concluded with a consensus view: private entrepreneurs in Wenzhou are excellent in managing market risks but rela- 
Table 2. Challenges for managing human Capital

\begin{tabular}{|c|c|c|c|}
\hline Items & Chongqing & Zhejiang & Total \\
\hline a. Lack of experiences for managing innovation & 2.62 & 3.24 & 2.92 \\
\hline $\begin{array}{l}\text { b. We are not sure whether there are talents wanted in the } \\
\text { market or not }\end{array}$ & 2.27 & 3.25 & 2.78 \\
\hline $\begin{array}{l}\text { c. We are sure that there are talents wanted in the market, } \\
\text { but we can not find them }\end{array}$ & 2.55 & 3.37 & 2.95 \\
\hline $\begin{array}{l}\text { d. We can find talents wanted, but can not meet their salary } \\
\text { demands }\end{array}$ & 3 & 3.26 & 3.12 \\
\hline e. It's difficult to keep R\&D talents & 3.11 & 3.3 & 3.19 \\
\hline $\begin{array}{l}\text { f. We can not prevent } R \& D \text { talents from letting out some } \\
\text { technical secrets after their resignation }\end{array}$ & 3.39 & 3.55 & 3.46 \\
\hline
\end{tabular}

NOTE: 1. not a concern; 2. small concern; 3. important concern; 4. very important concern; 5 . extremely important concern.

SOURCE: World Bank SME innovation survey, 2007.

tively poor in managing innovation risk. Many firms lack management personnel who understand the risks, process and key ingredients of innovation and know how to effectively apply new technologies to enhance their process and products. This situation seems common to private SMEs operating in traditional sectors in other parts of China as well. The World Bank 2007 survey shows that "lack of experiences for managing innovation" is an important concern for SMEs though it is not the most important concern in human capital constraints. In Zhejiang, this constraint seems even bigger (Table 2 above). A sector-based analysis of the survey results shows that human capital constraints seems especially serious for "home appliances", "agriculture", "textile and garments", and "daily grocery and other light industries" (Table 3). To help strengthen the innovation management capacity of entrepreneurs and senior managers is a critical task for government.

- Adapting to the labor market conditions. Labor market provides the channel for SMEs to tap into the regional and national pools of R\&D talents. However, given the developing nature of the Chinese labor market, SMEs must be adaptive to market conditions in order to find and get the talents they need. This includes for example utilizing head hunting services. To establish regular exchange channels with universities and training institutions as well as employment centers are very important. Given the increasing popularity of the Internet job market, SMEs also need to take advantage of the new technology to advertise positions and locate the talents they need. Adequate provision of related services is also equally important.

To help the SMEs better manage and tap into the limited talents pool, one 
Table 3. Challenges for Managing Human Capital (Sector-based Analysis)

\begin{tabular}{l|l|l|l|l|l|l|l|l|l|l}
\hline & S1S1 & S2 & S3 & S4 & S5 & S6 & S7 & S8 & S9 & S10 \\
\hline $\begin{array}{l}\text { a. Lack of experiences for } \\
\text { managing innovation }\end{array}$ & 1.89 & 2.75 & 1.81 & 2.15 & 3.42 & 1.72 & 3 & 3 & 3.65 & 2.92 \\
\hline $\begin{array}{l}\text { b. We are not sure whether there } \\
\text { are talents wanted in the market } \\
\text { or not }\end{array}$ & 1.68 & 2.23 & 1.87 & 2 & 2.89 & 1.13 & 3.5 & 2.83 & 3.31 & 2.9 \\
\hline $\begin{array}{l}\text { c. We are sure that there are talents } \\
\text { wanted in the market, but we } \\
\text { can not find them }\end{array}$ & 2.2 & 2.53 & 2.24 & 2.17 & 3 & 1.88 & 3.25 & 2.5 & 3.44 & 2.87 \\
\hline $\begin{array}{l}\text { d. We can find talents wanted, } \\
\text { but can not meet their salary } \\
\text { demands }\end{array}$ & 2.84 & 2.99 & 2.06 & 1.88 & 2.63 & 2.36 & 2.75 & 2.67 & 3.25 & 3.12 \\
\hline \begin{tabular}{l} 
e. It's difficult to keep R\&D talents \\
\hline $\begin{array}{l}\text { f. We can not prevent R\&D talents } \\
\text { from letting out some technical } \\
\text { secrets after their resignation }\end{array}$
\end{tabular} & 2.87 & 3.5 & 2.94 & 2.89 & 2.83 & 2.63 & 4.25 & 4 & 3.18 & 3.36 \\
\hline
\end{tabular}

NOTE: 1. 1. not a concern; 2. small concern; 3. important concern; 4. very important concern; 5. extremely important concern.

2. S1: IT (telecommunications, computer, software, system integration, etc.); S2: Machinery (including auto); S3: Medicine; S4: Chemical (including petrochemical); S5: Food and beverage (including liquid); S6: New material, new energy, and environmental technology; S7: Home appliance; S8: Agricultural; S9: Textile and Garment; S10: Daily grocery and other light industries.

SOURCE: World Bank SME innovation survey, 2007.

possible measure is to:

1) Establish at least one SME Skills Development Center in each province. Such a center should be public-owned but privately operated, and can be established with the assistance of the World Bank. Its purpose can be three-folded. First, providing various management and technical training, especially related to innovation, such as entrepreneurship, human resources management, innovation risk management, fund-raising, venture capital, IPR, technology commercialization, etc. The curricula should be market driven, and developed by the first-class experts and entrepreneurs. A common complaint of the current training programs is their low quality and low relevancy, therefore, to ensure the market-orientation is the key for its success. A potentially useful model is the Penang Skills Development Center (PSDC) in Malaysia. PSDC "operates as a non-profit organization ‥ Participating companies pool their resources together to help plan, design and conduct an extensive range of training programs directly relevant to immediate and forecasted needs. This enables PSDC to offer the most cost-effective training for the industry and at the same time bridge the gap between skills taught in public institutions and skills acquired on the job." 4 Second, 
providing information on skills demand and supply and premium on different job categories, through close relationship with schools, training institutions and the labor market. The major service focuses on information, but not the real headhunting services, which can be taken by the market. Third, collecting and disseminating success cases in terms of talents management and promoting innovation culture, especially those from inside China, such as NeuSoft (Box 1). This dissemination can be done through the center's training program.

\section{Box 1. AdDressing the TAlent Shortage}

As a result of talent shortage, China's high-tech companies face acute challenges in all three of the critical human resources staffing functions: recruiting, development, and retention. However, some leading companies, like NeuSoft, have developed a comprehensive approach to all aspects of the talent issue.

Founded in 1991, NeuSoft originated from Northeastern University. Over more than a decade's development, NeuSoft has grown to become a comprehensive solution provider with software technology as its core, with software and services, medical systems and IT education and training as its main business fields. With $\$ 305$ million in 2005 revenues, NeuSoft has emerged as a formidable competitor to software firms in the U.S. and India.

NeuSoft's talent strategy emphasizes financial rewards, company culture, and the opportunity for growth and learning to hold on to its key employees:

- Rewards. When NeuSoft went public in 1996, it created through stock options some of China first millionaires. The company has continued to find innovative ways of holding on to employees by delivering excellent compensation.

- Company culture. NewSoft has a Department of Branding and Culture, responsible for providing social events and entertainment, organizing sports teams, and providing a comprehensive employee website for the company's geographically dispersed workforce. As a result, NeuSoft employees have a strong bond with the company. NueSoft's stated values of transparency, directness, and trust reinforce the way that software engineers work together to develop superior products.

- Opportunities for growth. NeuSoft's extraordinary growth over fifteen years has meant unique career opportunities for young Chinese. The employees are given work that is as challenging as they can possibly handle, and permitted great room for them to grow.

As a result of the company's talent strategy, most key employees have stayed at NeuSoft. Turnover has always been very low: $2-3 \%$ during the early years; now it is $9 \%$, compared to an average of $25 \%$ in the regions where NeuSoft operates.

SOURCE: Heidrick and Struggles, "Getting Results in China: How China's Tech Executives are Molding A New Generation of Leaders?" Heidrick and Struggles Leadership Consulting and the Stanford Project on Regions of Innovation and Entrepreneurship, 2006. 
2) Provide strong incentive for enterprise training. Currently the government provides certain tax incentives, but the tax deductible training expenses cannot exceed $2.5 \%$ of the total enterprise wages. 5 Also for technology enterprises, the tax credits for hiring technology personnel is not based on the real wages of these personnel, but based on an ad hoc amount-about RMB 1,600/month per person, much lower than the typical real wage level for technology firms. All these have to be reformed to better encourage firms to hire S\&T personnel and participate in in-house or out-house training. Of course, these reforms should come hand in hand with better monitoring and evaluation system to prevent firms taking advantages of these incentives.

3) Formulating and implementing training standards. Given the various training and certificate programs, it's hard to assessment their qualities and relevance to the labor market. It's important for the government agencies, such as the Ministry of Labor and Social Security and Ministry of Education to work with various industrial associations and standards and metrology organizations to develop and enforce unified training standards in order to ensure the training quality.

\section{ENCOURAGING COLLABORATION WITH UNIVERSITIES AND S\&T INSTITUTES}

To build their own innovative capability, SMEs need to access external sources of information, knowledge, know-how and technologies. Collaboration with universities and S\&T institutes is a primary way for SMEs to tap into knowledge and technologies. In most cases in China, collaboration is facilitated by market-based contract. The extent to which SMEs can benefit from such collaboration depends on how skillful SMEs are in managing such contract on one hand, and the attitude and behavior of universities and S\&T institutes on the other hand. The World Bank 2007 survey shows that the major areas that firms cooperate with universities and research institutes are "technical consulting", "joint research", and "training", and over $16 \%$ of the surveyed SMEs do not have any kind of cooperation with universities or research institutes. Various disincentives and obstacles, such as a lack of motivation, an inability to identify and specify needs, and a lack of certain competencies, deter most SMEs from taking full advantage of networking or other opportunities.

According to a study by the Chinese Academy of Social Sciences on the competitiveness of Chinese private enterprises, the Chinese private enterprises are quite weak and constrained in terms of collaboration and cooperation with other enterprises and knowledge institutions. More specifically:

1) There is no institutionalized platform for private enterprises to conduct collaboration and exchanges with other enterprises (including SOEs) and 
R\&D institutions. Most private enterprises still carry out innovation activities in an isolated way.

2) The still existing social stereotype and discrimination against private enterprises (most of them are SMEs) make it harder for them to establish formal collaboration mechanisms, though this situation has been improving.

3) Constrained by their own limited innovation, absorption and learning capacities, private enterprises have great difficulties establishing broad collaboration and cooperation networks and mechanisms with innovation-related institutions.

4) The current collaborations and cooperation between private enterprises and other innovation partners lack long-term benefits-sharing mechanism and are vulnerable to any interest dispute. ${ }^{6}$

The World Bank 2007 survey shows the execution of cooperation contracts between firms and universities/research institutes is far from satisfactory-almost $50 \%$ of the surveyed firms answered "so-so" or less (Table 4). The service qualities of universities/research institutes are also problematic-over $55 \%$ of the firms rated the services as "so-so" or less (Table 5).

Table 4. The Execution of Service Contracts Between Firms and UNIVERSITIES/ RESEARCH INSTITUTES

\begin{tabular}{l|c|c|c}
\hline & Chongqing (\%) & Zhejiang (\%) & Total (\%) \\
\hline & 100 & 100 & 100 \\
\hline 0. No such kind of contracts & 23.8 & 25.6 & 24.6 \\
\hline 1. Very bad & 0.5 & 3.2 & 1.7 \\
\hline 2. Bad & 8.9 & 12.8 & 10.6 \\
\hline 3. Just so-so & 34.7 & 38.5 & 36.3 \\
\hline 4. Very good & 25.7 & 13.5 & 20.4 \\
\hline 5. Excellent & 6.4 & 6.4 & 6.4 \\
\hline
\end{tabular}

SOURCE: World Bank SME innovation survey, 2007.

Table 5. The Service Quality of Universities/Research Institutes

\begin{tabular}{l|c|c|c}
\hline & Chongqing (\%) & Zhejiang (\%) & Total (\%) \\
\hline & 100 & 100 & 100 \\
\hline 0. No such kind of contracts & 19.4 & 25.2 & 21.9 \\
\hline 1. Very bad & 0.5 & 1.3 & 0.8 \\
\hline 2. Bad & 8.5 & 9.0 & 8.7 \\
\hline 3. Just so-so & 46.3 & 45.8 & 46.1 \\
\hline 4. Very good & 22.9 & 11.0 & 17.7 \\
\hline 5. Excellent & 2.5 & 7.1 & 4.5 \\
\hline
\end{tabular}

SOURCE: World Bank SME innovation survey, 2007. 
Although the share of firms outsourcing S\&T activities to the science sector is increasing over time and about $23 \%$ of S\&T firms were conducting S\&T outsourcing to universities or research institutes in $2002,{ }^{7}$ the industry-academy-research linkage is undermined by the lack of credibility of related parties, and short-term focus. Enterprises tend to consider if the cooperation project can bring in profits immediately, and academia tend to focus on weather such projects can quickly bring them higher professional title and personal benefits, thus, favoring those projects with few investments and short cycles and rapid to develop. ${ }^{8}$ Such behaviors seriously hinder productive collaborations between enterprises and research institutes/universities.

The torch program, launched in 1988, with the aim of developing new high-technologies industries in China, has boosted technology commercialization through venture investment by universities, the transfer of research results from universities and the Chinese Academy of Sciences, and the dual employment of professors and researchers.? All these efforts have led to many ventures launched from universities, including today's Lenovo, Founder, etc. However, due to its focus on new high-tech spin-offs and high-tech parks, the program's effects on existing firms seem limited.

To facilitate SME participation in innovative networks, government initiatives may use more or less SME-specific targeted measures such as: raising awareness of networking opportunities and helping search for partners; organizing, financing and operating networks; interfacing scientific and innovation networks through public-private partnerships; and creating international linkages and building global networks. More specifically:

a) Increasing SME access to information. Many governments operate programs, such as Internet Portal-based services, to improve SME access to information about networking opportunities. A good example is Canada's Strategis and Innovation Portal launched in 1996 by Industry Canada, which includes a comprehensive inventory of links to innovative universities, public laboratories, federal and municipal agencies and businesses across Canada. The website includes information on business intelligence, financing, human resources, product development, marketing, intellectual property and research services. Also included are diagnostic tools and hundreds of subjects related to innovation. 10

b) Strengthening the technology "brokering" programs. Innovation brokers, if properly operated, can play very instrumental role in stimulating less innovative firms to start a learning process to become more innovative, as well as promoting the formation of networks and interactive learning among firms and knowledge institutions. A relevant example is the Norwegian TEFT (Technology Diffusion from Research Institutes to SMEs), which uses technology attaches as brokers (see Box 2). These attaches can be seen as prototypes for a proactive working method in performing their roles as analysts of 
firms, brokers and mediators. The program is able to mobilize less innovative SMEs to cooperate more with knowledge institutions through networks and perform joint innovation projects. However, it should be noted that the formation of such networks is a long-term process that requires active development of mutual interests and trust from both parties. ${ }^{11}$ China also has many technology diffusion organizations, such as engineering research centers and productivity centers, but they need to be reformed in the general framework of strengthening the innovation services as a whole. This will be further discussed in the section on innovation services.

\section{Box 2. The TEFT Technology Attaches as Brokers}

Started in 1994, TEFT (Technology Transfer from Research Institutes to SMEs) is a nation-wide program run by the Research Council of Norway (NFR), which aims to encourage SMEs to become more R\&D-conscious by developing closer links between such companies and the national technological R\&D institutes. It targets two groups of institutions. First is the non-R\&D intensive SMEs with weak internal resources, and the second group includes the five leargest polytechnic R\&D institutes in Norway, with the aim of changing their attitudes towards SMEs and strengthening their knowledge about SMEs' innovation needs. The program spans the whole spectrum of Norwegian industry, but is primarily intended to reach sectors with low or average levels of R\&D, and companies with 10-100 employees. Before a technology project can take place the enterprise is visited and evaluated by a county-based technology attaché. Each of the attachés seconded from R\&D institutes is responsible for a specific geographical area, and acts as broker, or as organizer, animator or coach in the innovation process of SMEs. The attachés have an active program of visits to companies and are normally the companies' first contact with the TEFT program. The attachés are in close touch with what is going on in Norwegian technological research institutes, and they put companies in contact with scientists, who will carry out the technology project in close co-operation with the company. The TEFT program pays $75 \%$ of project costs, while the remaining $25 \%$ is covered by the company itself. Financial support from TEFT will usually come to between EUR 4,000 and EUR 13,000 .

Through these instruments, TEFT is able to help lower barriers to cooperation between national R\&D institutes and SMEs, with the attaches acting as brokers, and in that way to encourage SMEs to use R\&D institutes and to strengthen industry-science relations.

SOURCE: OECD, Global Knowledge Flows and Economic Development, Paris, 2004; EC, Directory of Measures in Favor of Entrepreneurship and Competitiveness, Enterprise and Industry Department, 2002. http://ec.europa.eu/enterprise/enterprise_policy/charter_directory/en /technology/norway.htm.

c) Increasing SMEs participation in public-private partnerships (PP/Ps). Involving SMEs in PP/Ps is essential for the stimulation of technological entrepreneurship, for gaining access to knowledge sources, and for linking science-based innovation networks to less $\mathrm{R} \& \mathrm{D}$ intensive ones. As, traditionally, SMEs are not very present at the interface between science and innovation systems, 
an accentuated "revealed preference" of government-financed business R\&D for small firms can be observed in many countries, and attenuates the "bias against SMEs." In France, for example, the share of SMEs in the government financing of 13 French public/private research networks accounted for $29 \%$ in 2001, only second to public research labs (36\%) (Table 6). In Netherlands, the government is paying increased attention to the involvement of new and established SMEs in forming PP/P schemes. It also applies a new scheme for SMEs to receive innovation vouchers to be spent on public research, whether basic or applied. ${ }^{12}$

Table 6. Share of SMEs in the Financing of 13 French Public/Private RESEARCH NETWORKS, 2001 (MILLIONS OF EUR, \%)

\begin{tabular}{|c|c|c|c|c|c|c|c|c|c|c|}
\hline \multirow[t]{2}{*}{ Type of recipient } & \multicolumn{2}{|c|}{ Life sciences ${ }^{1}$} & \multicolumn{2}{|c|}{$\begin{array}{l}\text { Energy, transport, } \\
\text { environment, } \\
\text { natural resources }\end{array}$} & \multicolumn{2}{|c|}{$\begin{array}{c}\text { Information and } \\
\text { communication } \\
\text { technologies }^{3}\end{array}$} & \multicolumn{2}{|c|}{$\begin{array}{l}\text { Space and } \\
\text { aeronautics }\end{array}$} & \multicolumn{2}{|c|}{ Total } \\
\hline & EUR & $\%$ & EUR & $\%$ & EUR & $\%$ & EUR & $\%$ & EUR & $\%$ \\
\hline $\mathrm{SMEs}^{4}$ & 11.39 & 43 & 4.34 & 25 & 7.34 & 19 & 1.78 & 35 & 24.84 & 29 \\
\hline Large firms ${ }^{5}$ & 0.37 & 1 & 1.71 & 10 & 6.76 & 18 & 0.11 & 2 & 8.95 & 10 \\
\hline Public research labs & 11.15 & 42 & 6.60 & 38 & 12.55 & 33 & 1.38 & 27 & 31.67 & 36 \\
\hline Higher education & 1.43 & 5 & 2.62 & 15 & 7.08 & 19 & 0.75 & 15 & 11.88 & 14 \\
\hline Engineering schools & 0.93 & 3 & 0.83 & 5 & 2.88 & 8 & 0.60 & 12 & 5.25 & 6 \\
\hline Others & 1.39 & 5 & 1.32 & 8 & 1.09 & 3 & 0.46 & 9 & 4.27 & 5 \\
\hline Total & 26.65 & 100 & 17.43 & 100 & 37.69 & 100 & 5.09 & 100 & 86.86 & 100 \\
\hline
\end{tabular}

NOTE: 1. RNTS, GenHomme, Génoplante, RARE.

2. PREDIT, Pile à combustible, Matériaux, Génie civil, Eau et environnement, Pollution accidentelle.

3. RNRT, RNTL, RMNT.

4. Enterprises with fewer than 500 employees.

5. Enterprises with more than 500 employees.

SOURCE: French Ministry of Research; OECD, OECD SME and Entrepreneurship Outlook 2005.

d) Developing personnel mobility schemes. Such programs should encourage enterprises to give internships to graduate engineering students or research scientists, and allow researchers at universities or research institutions spend several months on sabbatical working in enterprises, and vise versa, allow engineers and technical personnel at enterprises to spend some time at universities or $\mathrm{R} \& \mathrm{D}$ institutes. In order to support the human resources mobility between public research institutions and private sector companies, many OECD countries have adopted measures like temporary placements and industry-funded Ph.D projects. ${ }^{13}$ One example of good practice is the UK's Business Fellowship scheme through which mainstream academics become business fellows, and are enabled to spend part of their time advising companies 
on technical or research problems in response to the enterprise's needs. Regulation and incentives may be instruments for attracting more SMEs. In Denmark, a tax deduction on collaborative R\&D has been introduced. In Belgium, the First-Enterprise scheme covers up to $80 \%$ of the salary for two years of a young researcher working part-time in an SME and part-time in a research lab. The researcher engages in a specific research project in the firm. Other eligibility criteria for access to a First project is that the researcher should spend enough time in the hosting research institute to allow a real knowledge transfer to the firms, and that the research team is competent in the relevant research field and motivated to engage in innovation projects in the firm. ${ }^{14}$

e) Encouraging universities and $R \& D$ institutes to conduct more joint $R \& D$ activities with enterprises. With the "pushing to the market" reform, Chinese $\mathrm{R} \& \mathrm{D}$ institutes and universities have strengthened their cooperation with enterprises. However, by looking at the shares of revenues of universities and $R \& D$ institutes generated from serving enterprises, we found that the share for universities has increased from 4.5 billion yuan in 1999 to 14.4 billion yuan in 2004 , increasing by $22.4 \%$ on average, and accounted for about $41.8 \%$ of total university S\&T revenues, while the share for R\&D institutes was only $7.0 \%$ in 2004 , increasing by $4.7 \%$ on average from 1999-2004.15 The figures for SMEs are not available, but it can be assumed that the majority SMEs are not conducting R\&D activities with universities and $R \& D$ institutes, given their weak capacity. This shows there is still a lot of room to further encourage knowledge institutions, especially the government $\mathrm{R} \& \mathrm{D}$ institutes to have more enterprise-driven $\mathrm{R} \& \mathrm{D}$ activities. More tax and credits incentives can be implemented towards this end.

\section{PROMOTING CLUSTERS}

Clusters are defined by two key attributes namely geographical/spatial distribution and sectoral dimension. Here we mostly refer to those based on geographical proximity. Clusters enable enterprises to overcome many "binding constraints" in the areas of capital, skills, technology, knowledge, and market, etc, to grow and compete through more effective knowledge/technology diffusion, product specialization, leveraging local comparative advantage, fostering production value chains, and achieving collective efficiency. 16

In China, there are 53 government-approved Science and Technology Industrial Parks, including the renowned Zhongguancun Science Park in Beijing, as well as other regional development zones. These parks or zones have attracted and also incubated many technology firms, however, since these parks or zones are formed by policy intervention, the firms inside mostly operates in an isolated 
way and lack collaboration and cooperation. ${ }^{17}$ Therefore, the value chains required for a cluster have not or just being developed around these parks or zones. It will take time for them to evolve into true clusters though they have many critical elements of a cluster. Government can facilitate this development through certain measures, which includes creating a conducive business environment, strengthening the legal and IPR systems, improving the financial system, and boosting the innovation services, especially the inter-linkage services within the parks/zones. All these points are addressed in more details in different sections of the report.

In addition to these parks or zones, China also has many spontaneously formed enterprise clusters, especially in the coastal regions, such as Zhejiang, Guangdong, Jiangsu, etc. 18 They are mostly limited to the production of standardized consumer or low-technology goods made for mass markets (such as furniture, consumer electronics, and textiles and garments). There is usually little innovation, and $\mathrm{R} \& \mathrm{D}$ activity, if present at all, tends to be negligible. A subset of these firms may be integrated into global supply chains and shows strength, such as the Chongqing motorcycle cluster and Changzhou (Jiangsu Province) leather coat cluster, but in general such integration is limited, and the relatively homogeneous nature of their products makes them highly vulnerable to changes in demand from abroad. To the extent that firms seek to improve their competitive position, the strategy is often through cost-cutting measures, and there is not much inter-firm cooperation. Overall, there is complacency in the conduct of business, which is usually based on copying or licensing or products, using machinery imported from abroad. 19

These clusters mostly consisted of SMEs and are in general constrained by lack of access to information, finance, human capital, technologies, and various supporting services due to their ownership, size and informality. Most of them operate in low or medium technology sectors and lack R\&D capability and re-engineering skills. Many of them also suffer from weak corporate governance and management practice. China's underdeveloped financial system has a direct impact on SME business activity, since small firms-unable to bypass bank intermediation in order to raise funds directly from capital markets-are more likely to find that financial constraints are binding in the absence of bank loans.

To help upgrade the scale and technology level of the clusters and sustain their long-term growth dynamism, a systemic set of measures need to be taken, which include:

1) Strengthening regulatory environment for private businesses. These measures include the establishment of long-term consultation mechanisms between the local business community and local government, the removal of unnecessary bureaucratic procedures to promote efficiency, and the strengthening of agencies that assist in business formation at the local level. The CNSB Survey shows that "high government efficiency" is the foremost 
important factor for enterprises to establish innovation centers.

2) Stimulating inter-firm cooperation. This includes cooperation with firms both inside and outside a cluster. For small firms, perhaps the most effective channel to get new technologies is to cooperate with large firms to form joint ventures or to become a large firm's subcontractor. ${ }^{20}$ However, firms that have acted independently in the past will not easily switch to a mode of close cooperation. This is not only because of an absence of trust, but also since engaging in cooperation may involve high fixed as well as transaction cost. Therefore, government polices need to highlight the advantages of cooperation within the network cluster, perhaps by offering tax incentives. Alternatively, policymakers can adopt benchmarking with firms elsewhere (or with a world-class firm within the network cluster, if one exists), which may then clarify for firms just how far behind they are from the industry leaders. ${ }^{21}$ Meanwhile, to provide strong intermediary services is crucial for strengthening inter-firm cooperation, which is discussed in the next point.

3) Providing information, advisory, training and technology transfer services

\section{Box 3. Role of Local Industrial AsSociations in Wenzhou Footwear INDUSTRial Cluster}

Economies of agglomeration are an important but not sufficient condition for industrial growth and economic development. The footwear industry in Wenzhou developed from family workshops. Its fold character prevented heavy intervention by government forces in the early years when the government gave little help but posed no hurdles. The people of Wenzhou ran their businesses with wisdom, diligence, bravery and great creativity. They produced various pretty low-price commodities that attracted consumers. In the 1980s when shoes were in short supply in China, the major problems encountered by Wenzhou producers were related to credibility and reputation. The quality of product was somewhat poor, and inferior counterfeit products often appeared in the marketplace from black factories. In 1987 angry consumers burned down Wenzhou shoes at the City Gate of Hangzhou the provincial capital. The Wenzhou shoe industry was almost beaten until the Wenzhou Lucheng Association of Shoes Industry was organized in 1991, which has now 1,138 member enterprises and 26 association branches.

The Association first concentrated on enhancing the reputation of Wenzhou shoe products. Since its inception, the Association has made great efforts to improve shoe quality by training on production and design and introduction of advanced equipment. It organized local managers to visit their counterparts in the U.S., Italy and Korea, and has also helped member enterprises to expand sales channels-with annual shoe exhibitions in cities around China since 1996 and by contact with foreign counterpart such as the trade association of Italy. Its International Shoe Equipment Materials and Technology Exhibition has become one of the most professional exhibitions in Asia. Recently the Association organized the development of an electronic information network. The Association also acts as a bridge agency between the shoe industry and the government to exchange information on government policies and business needs.

SOURCE: Wang, Jici. 2006. China's Consumer-goods Manufacturing Clusters, with Reference to Wenzhou Footwear Cluster. Innovation: Management, Policy and Practice 8(1-2), July. 
within clusters. Due to limited capacity, SMEs have great difficulties accessing these services. This requires government to establish or strengthen various intermediary organizations that act as brokers in the formation of inter-firm networks within network clusters and provide various services. Industry or business-related associations, for example, can assist companies to link up with a range of support services. Technology intermediaries can help establish "innovation networks" that involve firms and knowledge institutions such as universities, R\&D institutes, and engineering consultancies to boost

\section{Box 4. Yunhe Wood Toy Cluster: Building InNovation Network}

China is one of the world's most important wood toy exporters. Its wood toy production is concentrated in Zhejiang province, especially in Yunhe county in the Southwest mountain area. It is known in China as "the hometown of wood toys." As early as the 1970s, some local firms in Yunhe had commenced toy production, and trade agents in Shanghai were responsible for product sales abroad. Massive development of the industry opened it to international trade in the ' $80 \mathrm{~s}$. The entry of private businesses altered the industry structure from previously state-owned and collective ownership, and a clustering division of labor evolved. A few of the largest enterprises in China, such as $\mathrm{XinYu}$ and $\mathrm{HeXin}$, produce end products, while small firms produce parts and components. Local suppliers for paint and adhesives and related services in transportation and package have also been established.

Recently with the support of local government and self-organization of producers, the technological infrastructure was strengthened. A Wood Toy Industrial Park came into existence in Yunhe in 1992. Since 1995, initiated by the toy industry association, the Yunhe Wood Toy Productivity Center, the Wood Toy Quality Testing Center, the Wood Toy Research Institute and the Wood Toy Information Center have been established. Yunhe now has the biggest toy manufacturing and export base in China. Its production capacity constitutes one-third of China's total. In 2003, more than 400 Yunhe wood toy producers produced outputs of 762 million yuan of which 454 million yuan was from exports, to 30 end consumers in North America, Europe and Japan. Back in 1983, outputs were 1.88 million yuan, and before 1973, they were a mere 0.1 million yuan.

Among Yunhe's key success factors are linking with domestic knowledge centers and learning from global value chain. In order to improve design and other technological capacities, in addition to its own $R \& D$ through research institute and productivity center, etc., the cluster has built cooperative relations with Tianjing University of Science and Technology and Zhejiang University of Technology. The cluster also interacts with national agents such as the China Light Industry Association and the National Technical Committee of Standardization for Toy Industry. Visits and training programs by these agents in Yunhe have been very useful sources of learning. In addition, the cluster also learns from FDI, such as the HAPE International from Germany, and from international trade and expositions.

SOURCE: Zheng, Yanwei, and Shihao Sheng. 2006. Learning in a Local Cluster in the Context of the Global Value Chain: A Case Study of the Yunhe Wood Toy Cluster in Zhejiang, China. Innovation: Management, Policy and Practice 8(1-2), July. 
the innovation capacity within clusters. Good examples include Wenzhou footwear industrial cluster (Box 3) and Yunhe wood toy cluster (Box 4) in Zhejiang. Since these issues exist beyond clusters, we will further address them in the next section on services.

\section{ENHANCING INNOVATION SERVICES}

In China, innovation services have been generally weak or not given enough emphases. The intermediaries which provides policy advices, technical assistance, technology diffusion, standards and metrology, training, information, common and basic technology development and testing, technology forecasting, technology and IP assessment, legal and patenting assistance, financial advices, and head hunting, etc., as well as the technology market are quite weak. Many of these services have public good nature, and the government should finance, but their operations could be private.

Today, China's innovation services system consist of engineering research centers, productivity centers, incubators, S\&T consulting and assessment agencies, technology market, venture investment services, rural technology extension services, etc, which are intended to provide professional services for technology diffusion, commercialization, S\&T assessment, innovation resources allocation and management consultations. By 2004, there are about 70,000 various innovation intermediaries in middle and large size cities in China, employing about 1.2 million people. Among these organizations are 1,218 productivity promotion centers and 464 incubators (excluding 42 university high-tech parks). ${ }^{22}$

Despite the broad-range of innovation services agencies, their services seem far short of firms' satisfaction. The CNSB Survey shows that the average ratings of the surveyed firms towards various services providers are all under 3.5 on a range of 5 ( 5 is the best). For example, the ratings for "innovation service agencies", "S\&T consulting and assessment organizations", "S\&T information service organizations", and "technology market" are all 3.2. The World Bank 2007 survey also shows that majority firms find the innovation services are unsatisfying. In Zhejiang, the average scores are a little bit higher but all fall below 4 (satisfying) (Table 7).

The main constraint for most of the S\&T intermediary agencies is the lack of funding and qualified professionals. The mission of engineering research centers is to design and develop new technologies up to the demonstration stage, often jointly with enterprises, leaving commercialization and production to business. The centers should limit their activities to technical research, information, and assistance, with a clear focus on technologies for the public good. However, since they are mostly under-funded, they have to perform production activities rather than technology demonstration or pilot testing as intended. Productivity 
Table 7. Evaluations of China's Innovation Services

\begin{tabular}{l|c|c|c}
\hline & Chongqing & Zhejiang & Total \\
\hline Technical consulting and training & 3.01 & 3.52 & 3.25 \\
\hline Information & 2.87 & 3.45 & 3.14 \\
\hline Testing and processing center & 3.14 & 3.61 & 3.36 \\
\hline $\begin{array}{l}\text { Technology and intellectual property } \\
\text { assessment and technology transfer }\end{array}$ & 2.56 & 3.30 & 2.91 \\
\hline Legal and patents services & 3.33 & 3.65 & 3.47 \\
\hline Head-hunting & 1.80 & 3.30 & 2.50 \\
\hline Finance and investment consulting & 2.49 & 3.39 & 2.91 \\
\hline Credit Guarantee Institutions & 2.30 & 3.34 & 2.78 \\
\hline Industry association & 3.06 & 3.64 & 3.33 \\
\hline Productivity centers & 2.86 & 3.35 & 3.06 \\
\hline Incubators & 2.32 & 3.38 & 2.75 \\
\hline
\end{tabular}

NOTE: 1. no demand for such services; 2. never used such services; 3 . unsatisfying; 4 . satisfying; 5. very satisfying.

SOURCE: World Bank SME innovation survey, 2007.

centers have also been established to provide comprehensive services, such as technology information, consulting, innovation support, to SMEs and TVEs. Because they also need to self-finance most of their operations, they too have also entered business and production activities to pay their personnel. ${ }^{23}$ Meanwhile, these organizations and other technology-related services also have difficulty recruiting highly qualified professionals. This is due to both funding and skills shortages. The problem of lack qualified professional also applies to other non-technological service agencies, such as legal, patenting, and financial services, but mostly because of the skills shortage on the market.

In a broader context, there is a social bias against the intermediary services. Traditionally Chinese society tends to put more emphasis on tangible assets and neglect "soft" areas, especially the intermediary services, which are generally undervalued or even unappreciated. Such a bias also contributes the constraints mentioned above.

As a result, the roles of business or industrial associations are pretty weak in general and couldn't fulfill the functions that they are normally supposed to fulfill in Western countries. The standards and metrology services also suffer from under-funding and understaffing, as well as weak monitoring and evaluation systems. More often than not, enforcement mechanisms are ineffective or inconsistent. Product certification is rather obscure, in many cases using arbitrary criteria. 24 All these situations seriously constrain the technology diffusion and commercialization process. 
In order to strengthen the overall innovation services, certain measures need to be taken.

1) Strengthening government support for innovation services, especially the technology diffusion agencies. Current government incentives and preferential policies mostly target the research institutions and enterprises, but not much on the intermediary services. In order to strengthen this sector overall, government needs to raise the awareness and officially acknowledge its importance for building an innovative economy with clear regulations and policies and grant them appropriate status and incentives, such as tax benefits. For those providing public good services, such as the engineering research centers and productivity centers, government needs to give them the official non-profit organization (NPO) or public service unit (PSU) status and increase

\section{Box 5. The Industrial Technology Research Institute (ITRI) in Taiwan}

Government-supported technological and scientific research institutes acting as innovation intermediaries have been indispensable in Taiwan's high-technology industrial development. The Industrial Technology Research Institute (ITRI) and Electronics Research and Services Organization (ERSO), for example, based in Hsinchu, have played a major role in developing local technology capacities in firms.

Established in 1973, ITRI employs over 6,000 people, including nearly 5,000 R\&D staff ( 820 with Ph.Ds), and has an annual operating budget of $\$ 500$ million. Its technology focus ranges from the high-tech integrated circuit (IC) industry to the textile industry, and its work on factory automation ar.d advanced materials have also been applied in traditional industries. In 2002, it had a portfolio of nearly 1,000 U.S. registered patents. In 2001, ITRI provided training programs for 70,282 people and technical services (technological and managerial) to 30,427 companies; undertook contract research for 1,014 companies; and conducted joint $\mathrm{R} \& \mathrm{D}$ projects with 339 companies.

ITRI coordinates multi-partner consortia: the Taiwan New Personal Computer (TNPC) Alliance formed in 1993, for example, involved 31 partners including IBM, Apple and Motorola. The aims of the Alliance were to "bring together firms from all aspects of the IT industry with a clear focus on transferring, up-taking and diffusing the new PowerPC technology in a series of products spanning PCs, software, peripherals and applications such as multimedia." 25 The initiative behind TNPC lay with the Computer and Communications Laboratory, one part of ITRI.

As another example of its carefully developed role as an intermediary, in 1996 ITRI opened its Open Laboratory Program based in an extensive new R\&D complex in Hsinchu. The OpenLab Program mainly provides space and facilities for joint R\&D between ITRI researchers and local business, and also has space for business incubation, conference and training facilities. Firms in the incubator receive 'packaged' business and management consulting, financial and legal assistance, and office and administrative support. Entry to the business incubator requires the formal approval of a business plan. Such consultancy activity is subsidized by the government.

SOURCE: Dodgson, M., J. Mattews, and T. Kastelle. 2006. The Evolving Role of Research Consortia in East Asia. Innovation: Management, Policy and Practice 8(1-2), July. 
funding support. Sufficient core funding and adequately remunerated personnel are two of the prerequisites necessary for them to carry out their core functions. In recent years, a significant number of PSUs have been formally transformed into enterprises, and some have been privatized. In the S\&T sector, government stipulates that "those that provide public services to the society and cannot expect adequate economic return should be run and managed as NPOs." 26 It's important that the government maintains its support to the S\&T NPOs and do not privatize them. For those truly market-oriented services but still classified as PSUs or NPOs, government can gradually transform them into enterprises, as it has been doing in recent years. However, a rigorous assessment procedure should be implemented in the process and a thorough monitoring and evaluation system should be established to measure the performance of the publicly financed S\&T agencies. Good examples for technology intermediary services include the Industrial Technology Research Institute (ITRI) in Taiwan (Box 5) and the Fundacion Chile (Box 6).

\section{Box 6. Fundación Chile-A Path Breaker in Tapping Technologies and PROMOTING INNOVATIONS}

Fundación Chile is a privately-owned, non-profit technology center created in 1976 with a mandate of developing innovative businesses and programs by transferring technologies. Its mission is to contribute to the innovation in markets for goods and services and to transfer technologies aimed at providing Chile with added economic value. It focuses on improving the technical performance of economically important sectors by tapping first-class global technologies in creating new companies and joint ventures.

Its technology transfer mechanisms include:

- R\&D and adaptation of foreign technology for product and process innovation,

- Promotion of technology "consortium for pre-competitive horizontal R\&D."

- Technological antenna and technology diffusion to SMEs

- Institutional innovation (oriented to reducing transaction costs, market development in incomplete markets, public-private partnership for institutional development)

The systemic technology focus of Fundación Chile includes biotechnology, management, environment, financial engineering and information. Recent focus areas include forestry genetics and DNA vaccines for aquaculture.

Fundación Chile has developed the identification of missing links for developing clusters with comparative advantage into a business practice. The clusters include the agribusiness, marine, tourism (agro/eco), forestry and wood processing sectors. The Fundación applies the 'missing link' concept also in supporting education and human resources development.

Fundación Chile has been quite successful in incubating new ventures through entrepreneurship and technological innovation. By 1999, it had launched thirty-six such ventures. Seventeen have been sold. The six leading companies have generated more revenues than the total cost of the Fundación during its existence.

SOURCE: World Bank, Chile New Economy Study, LAC region, February 2004. 
2) Establishing a SME Innovation Service Fund. Such a fund can be established with the support of the World Bank, and aimed at enhancing the capacity of the innovation intermediary services. The functions of such a fund can be three-folded. First is to provide grants to those agencies, such as the engineering research centers, productivity centers and metrology institutes, on a competitive basis, accompanied with training and rigorous quality assurance and performance measurement systems. Second is to establish broad networks with universities and $\mathrm{R} \& \mathrm{D}$ institutes (including those abroad) to identify and recommend common key technologies for important industries or sectors for commercialization and further testing. This requires a group of very competent professionals, technologists and engineers. Third is to provide information services through establishing a nation-wide technology portal classified by sectors. It will provide a platform for all the R\&D institutes and universities to advertise their technologies and patents available, accompanied with detailed introduction. This service can be membership fee based. Meanwhile, it can host large scale technology fairs and expos to promote the linkage between enterprises and research institutes. This fund will be complementary to the current Innovation Fund for Small Technology-based Firms ${ }^{27}$ which mainly targets technology-intensive firms while the one we are proposing is intended to focus on the innovation services areas, especially the linkages within the innovation system which has more public good nature. Such fund can be piloted first in one or two provinces and then multiply into every province.

3) Improving the Measurements, Standards, Testing and Quality (MSTQ) services. Standards and quality are closely linked to innovation and productivity. Quality standards supported by a national metrology, standards, testing, and quality (MSTQ) system can contribute to enterprise competitiveness, innovation, and trade. They do so by improving information flows and allowing customer differentiation, thereby promoting quality and enhancing competition. Standards also embody technology, acting as a channel for technology diffusion and so enhancing productivity. ${ }^{28}$ China's MSTQ system, represented by The National Institute of Metrology, is relatively poor, dominated by the public sector, and lack adequate capacity (such as for accreditation and conformity assessments) and resources (both funding and staff) to meet the needs of fast-growing economy. In order to strengthen this system, government needs to take the following measures:

- Reviewing the functioning of all MSTQ programs, including their governance and management structures and effectiveness-with a view to improving their operational effectiveness and maximizing synergies between initiatives sponsored by various line ministries. Also, considering bringing under the purview of the State Bureau of Quality and Technical Supervision many accreditation programs set up and managed by various ministries, 
to foster national consistency.

- Increasing industry awareness of MSTQ services and their importance, including through better interaction with industry organizations and incentives (such as matching grants) for SMEs to use MSTQ services and obtain national and ISO certifications.

- Increasing funding and staffing support to metrology infrastructure, and encouraging private participation in testing and accreditation labs. Many government accreditation and testing labs could be considered for privatization or at least private management.

- Encouraging participation by Chinese scientists and MSTQ personnel (public and private) in international technical committees, working groups, workshops, and seminars.

4) Strengthening the technology market. In China, a technology market refers to physical entity to facilitate technology transactions between sellers and buyers. In 1984, the first technology market was created in Wuhan, which consisted of about 60 technology transfer offices in research institutes, universities and firms in this region. In 1992, Ministry of Science and Technology established the China Technology Market Association as a central organization to facilitate implementation of technology market policies all over China. Meanwhile, many regional technology market management and promotion organizations were established and regional governments made over 30 ordinances to assist the development of technology market. ${ }^{29}$ Since then, the technology market has been developing rapidly, with the total technology transaction amount growing on average at a rate of $15 \%$ in recent decades, increasing from 700 million yuan in 1984 to 133.4 billion yuan in 2004 . However, despite the development, the technology market is underdeveloped. Although there are about 60,000 technology exchange or trade organizations all over the country, ${ }^{30}$ they are not well recognized by enterprises and R\&D institutes, and lack qualified personnel. The lack of high-quality technology and IP assessment services and weak financial system also make it more difficult to conduct technology or IPR transactions. Normally it's hard to find very professional technology or IP assessment services, which can fairly price technologies or IPs to be traded, which undermines the credibility of technology markets and constrains its further development.

In order to remove these constraints, some measures can be taken. First is to properly fund and staff these technology markets to make sure they can provide professional and reliable services. In this regard, some joint training programs can be developed with foreign counterparts and domestic R\&D institutes and universities. Second is to strengthen the technology and IP certification and assessment services through strong partnership with $R \& D$ institutes, universities and private sector. A rigorous procedure must be implemented instead 
of making ad hoc decisions. If possible, to involve foreign experts could be an effective way to enhance the assessment qualities.

\section{Box 7. THE US SEMICONDUCTOR INDUSTRY ASSOCIATION}

The US Semiconductor Industry Association (SIA) is the premier trade association representing the U.S. semiconductor industry. Founded in 1977 by five microelectronics innovators, SIA unites 95 companies responsible for more than 85 percent of semiconductor production in this country.

The association provides domestic semiconductor companies a forum to advance the global competitiveness of the $\$ 80$ billion U.S. chip industry. Through a network of corporate CEOs and working committees, SIA shapes public policy on issues critical to the industry and provides a spectrum of services to aid members in growing their own businesses. The specific services include, but not limited to:

- Helping firms educate and recruit a highly skilled workforce.

- Providing advisory services in semiconductor technologies.

- Promoting fair and open trade.

- Helping provide safe working conditions in production facilities.

- Helping protect the environment.

- Tracking and distributing statistical information of market trends.

- Providing market research and policy consulting services.

- Organizing trade and investment events for member companies.

The Association has 10 working committees, which include:

- Public Policy: Focuses on legislative and regulatory issues that affect the semiconductor industry.

- Technology Strategy: Works to define strategies that promote and maintain U.S. world leadership in semiconductor technology.

- Environment: Identifies and address priority environmental issues at the federal, state and local levels.

- Safety and Health: Analyzes important issues that impact industry workers and surrounding communities.

- Workforce Strategy: Works to ensure sufficient numbers of relevantly educated and trained workers to support the industry's long-term growth.

- Industry Statistics: Develops statistical information about market conditions and product and industry trends to help companies make better business decisions.

- Communications: Promotes the objectives of the industry by developing strategic communications programs to highlight significant industry issues.

- World Semiconductor Council (WSC): Brings together the industry associations of the world's leading semiconductor producing nations to discuss important global policy issues.

- China and Japan Chapters: Allows SIA members to meet with local customers, government officials and industry executives.

Through working collaboratively with company representatives, the committees help the industry to make great progress in trade, technology, public policy, occupational safety and health, environmental concerns, industry statistics, and government procurement.

SOURCE: Author's compilation based on the SIA website. http://www.sia-online.org/home.cfm. 
5) Strengthening the industry associations. Industry associations play important roles in building bridges between government and the private sector and providing various services for its member firms, such as information services, policy and technology consulting, organizing trade and investment opportunities, and training. In China, industry associations traditionally belong to the government and do not have much autonomy. The heads of the associations are normally appointed by the government and are quite weak in representing the interests of the private sector. To fully unleash the roles of industry associations and enable them to better serve the needs of the private sector, China needs to give the industry associations more autonomy, and allow the enterprises and sectors to form their own associations and elect their own heads. Certain policy incentives such as tax benefits and competitive grants for non-for-profit organizations should apply to industry associations. The government can also encourage various trainings for staff working in associations so that they can fully perform their roles. Good examples of industry associations can be found in the U.S., such as the US Semiconductor Industry Association (Box 7).

In sum, in order to enhance the overall innovation capacity of Chinese enterprises, especially the SMEs, policy measures must be taken to enhance the human resources capacity, including the talents management and retention abilities; the linkages between industries and universities and research institutes; the cluster and value chains development; and innovation services at various fronts. In order for these policies to generate the best impact and sustainable effects, they need to be implemented in a systematic and well-coordinated way instead of in a piecemeal fashion.

\section{CONCLUSION}

Given the increasingly competitive international and domestic environment, China is at the critical stage of transforming its growth model from the current labor and capital-intensive one to a more knowledge and technology-based one. In order to successfully accomplish such a transition, China needs to significantly strengthen the innovation capacity of its enterprises. For small and medium-sized enterprises (SMEs), this is more of an issue of technology diffusion and absorption. This calls for a systemic policy intervention which may include, but not limited to: strengthening the talents management ability of and addressing skills shortage at SMEs through well-targeted and market-driven training programs (such as SME Skills Development Center); improving the institutional framework for innovation, especially the IPR protection; enhancing the enterprise-university/R\&D institutes linkages through institutional reforms and policy incentives; and bolster- 
ing innovation services, especially those of public goods nature, such as common and key technology testing and dissemination, technology assessment, information services, and MSTQ (metrology, standards, testing and quality).

To ensure the successful implementation of these policy measures, a strong partnership among the public, private and NGOs is critical. In addition, a sound monitoring and evaluation (M\&E) system need to be in place to safeguard the implementation process.

\section{REFERENCES}

China National Statistics Bureau. 2006. Research Report on China Enterprise Innovation 2006. internal document, November.

Huang, Can, et al. 2005. Organization, Program, and Structure: An Analysis of the Chinese Innovation Policy Framework. unpublished study.

ILO. 2002. Education and Skills in the People's Republic of China: Employers' Perceptions.

Kanamori, T., et al. 2006. China's SME Development Strategies in the Context of A National Innovation System. Asian Development Bank Institute (ADBI) discussion paper 55, September.

Liu, Yingqiu, and Z. Xu, ed. 2006. Report on Chinese Non-governmental Enterprises Competitiveness 3, Social Sciences Academic Press, Beijing.

Mathews, J. A. and Poon, T. S. Technological Upgrading through Alliance Formation: the Case of Taiwan's New PC Consortium. Industry of Free China 74(6): 43-58.

MOF and National Tax Administration. 2006. Notice on Preferential Tax Policies for Enterprise Technology Innovation.

MOST (Ministry of Science and Technology). 2006. China Science and Technology Development Report 2005. Science and Technology Literature Press, Beijing.

Motohashi, K. 2005. China's National Innovation System Reform and Growing Science Industry Linkage. draft, September.

OECD. 2004. Global Knowledge Flows and Economic Development, Paris.

OECD. 2005. OECD SME and Entrepreneurship Outlook.

World Bank. 2001. China and the Knowledge Economy: Seizing the 21 ${ }^{s t}$ Century, World Bank. 2005. China: Deepening Public Service Unit Reform to Improve Service Delivery, EAP.

World Bank. 2007. Unleashing India's Innovation Potential (forthcoming), SAR. Yao, Yang. 2003. In Search of Balance: Technological Development in China. WBI working paper, World Bank.

Zeng, Douglas Zhihua. 2007. Knowledge, Technology, and Cluster-based Growth in Africa. (forthcoming), World Bank.

Zhou, Yuan. 2006. Sub-national Innovation System Policy and Programs in 
China. National Research Center for Science and Technology for Development, unpublished paper, December.

\section{ENDNOTES}

1 The survey was designed by Douglas Zhihua Zeng and Chunlin Zhang at the World Bank, and conducted with the assistance of Chongqing Productivity Center, Zhejiang Administration Academy and Chinese Academy of Social Sciences.

2 ILO, Education and Skills in the People's Republic of China: Employers' Perceptions, 2002.

${ }^{3}$ China National Statistics Bureau. 2006. Research Report on China Enterprise Innovation 2006. internal document, November.

4 See website: http://www.logos-net.net/ilo/150_base/en/init/mal 5.htm.

s MOF and National Tax Administration, Notice on Preferential Tax Policies for Enterprise Technology Innovation, 2006.

${ }^{6}$ Liu, Yingqiu, and Z. Xu, ed., Report on Chinese Non-governmental Enterprises Competitiveness, No. 3, Social Sciences Academic Press, Beijing, 2006.

Motohashi, K. 2005. China's National Innovation System Reform and Growing Science Industry Linkage. draft, September.

8 Zhou, Yuan. 2006. Sub-national Innovation System Policy and Programs in China. National Research Center for Science and Technology for Development, unpublished paper, December.

9 Kanamori, T., et al. 2006. China's SME Development Strategies in the Context of A National Innovation System. Asian Development Bank Institute (ADBI) discussion paper 55, September.

${ }^{10}$ See website: http://strategis.ic.gc.ca/engdoc/main.html.

"OECD. 2004. Global Knowledge Flows and Economic Development, Paris.

12 OECD. 2005. OECD SME and Entrepreneurship Outlook.

${ }^{13}$ Huang, Can, et al. 2005. Organization, Program, and Structure: An Analysis of the Chinese Innovation Policy Framework. unpublished study.

${ }_{14}^{14}$ OECD. 2004. Global Knowledge Flows and Economic Development, Paris.

${ }^{15}$ MOST. 2006. China Science and Technology Development Report 2005, Science and Technology Literature Press, Beijing.

${ }^{16}$ Zeng, D. Zhihua. 2007. Knowledge, Technology, and Cluster-based Growth in Africa (forthcoming). World Bank.

${ }^{17}$ Liu, Yingqiu, and Z. Xu, ed. 2006. Report on Chinese Non-governmental Enterprises Competitiveness 3, Social Sciences Academic Press, Beijing

${ }^{18}$ The World Bank 2007 survey shows that about $55 \%$ of the surveyed firms in Zhejiang and Chongqing are is a cluster. The major reasons for firms not being in a cluster include "high moving cost", "small production scale", and "difficulty obtaining land", etc.

${ }^{19}$ Kanamori, T., et al. 2003. China's SME Development Strategies in the Context of A National Innovation System. Asian Development Bank Institute (ADBI) discussion paper 55, September.

${ }^{20}$ Yao, Yang. 2003. In Search of Balance: Technological Development in China. WBI working paper, World Bank.

${ }^{21}$ Kanamori, T., et al. 2006. China's SME Development Strategies in the Context of A National Innovation System. Asian Development Bank Institute (ADBI) discussion paper 55, September.

${ }^{22}$ MOST. 2006. China Science and Technology Development Report 2005, Science and Technology Literature Press, Beijing.

${ }^{23}$ World Bank. 2001. China and the Knowledge Economy: Seizing the $2^{\text {st }}$ Century.

${ }^{24}$ Ibid.

${ }^{25}$ Mathews, J. A. and Poon, T. S. Technological Upgrading through Alliance Formation: the Case of Taiwan's New PC Consortium. Industry of Free China 74(6): 43-58.

${ }^{26}$ World Bank. 2005. China: Deepening Public Service Unit Reform to Improve Service Delivery, EAP.

${ }^{27}$ See website: http://www.innofund.gov.cn/english/index.htm.

${ }^{28}$ World Bank. 2007. Unleashing India's Innovation Potential (forthcoming), SAR.

${ }^{29}$ Motohashi, K. 2005. China's National Innovation System Reform and Growing Science Industry Linkage", draft, September.

${ }^{30}$ MOST. 2006. China Science and Technology Development Report 2005, Science and Technology Literature Press, Beijing. 